\title{
El acceso a la información pública como derecho humano instrumental para la tutela del ambiente
}

\author{
POR CARLOS GONZALO F. FUENTES $(*)$ \\ Y MARÍA DE LAS NIEVES CENICACELAYA $(* *)$
}

\begin{abstract}
Sumario: I. Génesis del fenómeno en análisis.- II. Esencia del derecho de acceso a la información pública.- III. El derecho de acceso a la información pública como derecho humano.- IV. El Derecho de Acceso a la Información Pública en nuestro país.- V. El acceso a la información ambiental en el ámbito internacional.- VI. El acceso a la información ambiental en Argentina.- VII. Consideraciones conclusivas.VIII. Bibliografía.
\end{abstract}

Resumen: en el presente trabajo escogemos el fenómeno denominado "gobierno abierto", caracterizado por la apertura y transparencia del obrar del Estado, y la incidencia que presenta en su consolidación el Derecho de Acceso a la Información Pública en relación con la cuestión ambiental. A dichos efectos, haremos hincapié en la importancia del tema y su valor para el perfeccionamiento del sistema democrático, ello sobre la base de los principios jurídicos emanados de diversos instrumentos internacionales y de la jurisprudencia de Tribunales Internacionales que fueron caracterizando este Derecho Humano esencial para el logro de una sociedad participativa y plural. Con el propósito consolidar esta modalidad aperturista se deben diseñar herramientas que reduzcan la asimetría de poder entre el ciudadano y el estado. Este diseño está adquiriendo cada vez más importancia en relación con ciertas categorías claves de información, vinculada al ambiente y sus componentes; en dicho tópico centraremos nuestro trabajo.

(*) Prof. Derecho Constitucional y Derecho Público Provincial y Municipal, Facultad de Ciencias Jurídicas y Sociales, Universidad Nacional de La Plata, UNLP. Docente Investigador Programa de Incentivos Categoría V. Director del Observatorio de Asuntos Federales, Facultad de Ciencias Jurídicas y Sociales, Universidad Nacional de La Plata, UNLP.

(*) Doctora en Ciencias Jurídicas y Sociales, Universidad Nacional de La Plata, UNLP. Prof. Titular Ordinaria Derecho Constitucional, Facultad de Ciencias Jurídicas y Sociales, Universidad Nacional de La Plata, UNLP. Docente Investigador Programa de Incentivos Categoría II. 
Palabras claves: Estado Abierto - información pública - participación ambiente - ciudadanía

\section{Freedom of information: an instrumental human right to protect environment}

Abstract: in this paper we analyze the issue of open government and how environment transparency is strengthened by freedom of information. Specific attention will be focused indeed on its value as a democratic tool, specially taking account of the most important international treaties on human rights and international decisions. In this sense, it is necessary to improve legal mechanisms in order to empower weak citizens as compared with a strong state. In view of the above, a certain kind of information - which is related to environment, for instance- is extremely significant. We will approach to this issue.

Keywords: Open State - public information - participation - environment citizenship

\section{Génesis del fenómeno en análisis}

Como dato esencial en la evolución del fenómeno denominado "gobierno abierto" debemos comprender que el mismo es el producto directo de los reclamos del pueblo efectuados en el marco de lo que Rosanvallon (2007) denomina "sociedad de la desconfianza", en la cual se acrecienta el permanente estado de sospecha de la ciudadanía en relación con el poder estatal.

Frente a dicha situación, Oszlak (2016) afirma que el mundo está atravesando una época de apertura institucional inédita, hoy el adjetivo "abierto" califica toda clase de objetos e instituciones. Además de datos abiertos y gobierno abierto, se habla de parlamento abierto, justicia abierta, democracia abierta, ciudades abiertas, universidades abiertas, servicios públicos abiertos e innovación abierta. En dos palabras, sociedades abiertas.

Es fundamental que el reconocimiento legal a la libertad de información y la concepción del gobierno abierto alcance a las demás instituciones del Estado. Por ello, es que en la actualidad se comienza a hablar del término "Estado abierto" para aludir a un fenómeno común: promover la apertura de los repositorios de datos, el acceso ciudadano a la información, la participación social en la elaboración de políticas, la rendición de cuentas y, en general, el control ciudadano de la gestión pública y sobre la trasparencia en el manejo de la cosa pública.

Definitivamente, remarca Oszlak, el culto a la apertura parece haberse instalado en el discurso político, reivindicando el derecho ciudadano a la información 
sobre los asuntos públicos, paso ineludible en el tránsito hacia una democracia deliberativa. Aquí yace la raíz del tema que nos proponemos desplegar.

En ese orden de ideas, en el marco de la consolidación de esta modalidad de apertura del Estado, resulta de suma importancia la forma en la cual el ciudadano puede vincularse con la información en manos de quienes con su obrar - directo o indirecto- inciden en los asuntos que componen el bien común estatal. Cuanto mayor y mejor información se cuente, mejor se podrán ejercer todos los derechos, desde expresarnos libremente, elegir a nuestros representantes, acceder igualitariamente a la educación y a la salud hasta gozar de un ambiente adecuado (Martín Mateo, 1991). En relación con lo último, cabe recordar que fueron precisamente ambientalistas organizados los pioneros en poner en la agenda pública la necesidad de garantizar el acceso a la información para poder controlar toda actividad —pública o privada - que pudiera poner en riesgo al ambiente (Saba, 2004).

\section{Esencia del derecho de acceso a la información pública}

Resulta un dato habitual que los gobiernos operen en el secretismo y la opacidad, aislando a los ciudadanos de la información que les permite ser protagonistas en el manejo de la cosa pública. Cuando la información en poder del Estado no es accesible, es difícil de obtener, o es secreta, oscura o imprecisa, el ciudadano pierde mucho más que la posibilidad de conocer un dato en particular: su vulnerabilidad se acrecienta.

$\mathrm{Al}$ respecto, Norberto Bobbio (2013) afirmaba que la democracia es idealmente el gobierno de un poder visible, cuyos actos se realizan ante el público y bajo la supervisión de la opinión pública. Por ello, afirmaba que la opacidad del poder es la negación de la democracia. El acceso a la información es una de las muchas formas del derecho que un Estado democrático reconoce solo a los ciudadanos - sea que los considere singularmente o en conjunto como 'pueblo' - de vigilar a los vigilantes.

La información "empodera" con información, no solo adquirimos conocimientos: podemos formarnos una opinión, tomar decisiones genuinamente, y también ejercer con mayor responsabilidad nuestros deberes. La importancia de la información fue definida de manera contundente por el recordado Carlos S. Fayt (2005), al sostener que aquella le permite al administrado organizar su vida y sus conductas y mantener relaciones de convivencia con los demás ciudadanos.

La información que está en manos del Estado es propiedad de los ciudadanos, razón por la cual, el acceso a la información pública no es una concesión graciosa del Estado sino un derecho humano fundamental. Y no solo un derecho individual, ya que, como se vislumbra, se encuentra asociado al interés público por 
ser precondición de la democracia, del debate abierto de ideas y del control del gobierno.

Por ser precisamente un derecho esencial para la formación de una opinión pública robusta, es que el derecho de acceder a la información pública tiene un valor esencial que el Estado tiene el deber de proteger. Y, si es un derecho al que se dota de especial protección - nacional e internacional- no es por los sujetos titulares, sino precisamente por la función que su ejercicio tiene en el sistema político (Basterra, 2006).

En su faz colectiva, el acceso a la información pública permite un diálogo entre la ciudadanía y sus gobernantes, cultivando la buena gobernanza y fomentando un clima político de apertura, transparencia y participación, todo ello base de una democracia legítima. Solo una ciudadanía que está bien informada puede contribuir de forma efectiva al proceso de toma de decisiones que afectan su futuro (Mendel, 2009).

La ciudadanía en la sociedad de la información está asumiendo que tiene el derecho a que el Estado le brinde información. Investigadores, periodistas, historiadores, activistas de derechos humanos, empresarios, o cualquier persona que quiera saber sobre cualquier tema de su interés puede pedir información al Estado y este está obligado a proporcionarla.

El Derecho de Acceso a la Información Pública (DAIP) se erige así en una herramienta que facilita la participación activa e informada sobre el diseño de políticas, planes y medidas públicas que afectan directamente a la población. Sin la posibilidad de recibir información, que se encuentra en poder del Estado, los beneficios políticos que se derivan de un clima de libre expresión no pueden realizarse plenamente (Nino, 2008).

De tal modo, la participación es central para tomar decisiones sólidas y justas en términos del desarrollo(1).

Asimismo, cobra cada vez más importancia una novedosa dimensión del derecho de acceso a la información en poder del Estado, que es la que se relaciona con la obligación positiva y sustantiva de los Estados, de asegurar que ciertas

(1) Así lo ha entendido precisamente el Programa de Naciones Unidas para el Desarrollo al señalar tres beneficios clave de la participación democrática: ser en sí mismo un derecho humano fundamental del que todos deben disfrutar; proteger contra catástrofes; y poder desencadenar un ciclo positivo de desarrollo. Y como el acceso a la información sostiene una participación eficaz, también contribuye a estos resultados. Informe sobre Desarrollo Humano 2002. Profundizar la Democracia en un Mundo Fragmentado, Programa de Naciones Unidas para el Desarrollo, New York, 2002. 
EL ACCESO A LA INFORMACIÓN PÚBLICA COMO DERECHO HUMANO INSTRUMENTAL PARA LA TUTELA DEL AMBIENTE - CARLOS GonZAlo F. Fuentes

y María de las Nieves CeniCACElaya (PP. 171-194)

categorías clave de información estén disponibles para su ciudadanía: las relativas a violaciones de los derechos humanos y las referidas a amenazas para el ambiente. Tales variables, nos proponemos dilucidar en el presente desarrollo.

\section{El derecho de acceso a la información pública como derecho humano}

El DAIP es un derecho humano fundamental, de carácter universal y de sustantiva importancia como herramienta de participación necesaria para el ejercicio de una ciudadanía plena en toda sociedad democrática. Forma parte de los derechos innatos, imprescindibles e irrenunciables del ser humano, que deben ejercerse en condiciones de igualdad, y de cumplimiento obligatorio por parte de los Estados (Nikken, 1994).

Mediante el mismo, se asegura el acceso a los documentos y archivos en manos del Estado, en pos de garantizar el derecho de las personas a mejorar su calidad de vida y favorecer la toma de decisiones. El DAIP constituye, entonces, un atributo natural de la condición de ciudadano, puesto que deriva del principio de soberanía popular y de la forma republicana de gobierno, que supone la publicidad de los actos de gobierno y la transparencia en la gestión pública.

El DAIP se convierte en el epicentro de la progresiva evolución de un conjunto de derechos y libertades esenciales del sistema democrático, como lo es la libertad de expresión, opinión y pensamiento, la libertad de imprenta y de prensa, el derecho a la información y el derecho a la comunicación. Este derecho tiene un impacto claramente positivo en al menos tres diferentes esferas de acción social: la política, la económica y la administración pública (Ackerman y Sandoval, 2005).

Ackerman y Sandoval (2005, p. 15) nos recuerdan que hace ya más de tres décadas, la Corte Suprema de la India sostuvo que

Cuando una sociedad haya decidido aceptar a la democracia como su fe fundamental, es elemental que sus ciudadanos conozcan lo que su gobierno está haciendo (...). Ningún gobierno democrático puede sobrevivir sin rendición de cuentas y el postulado básico de la rendición de cuentas es que el pueblo cuente con información acerca del funcionamiento del gobierno. Únicamente si el pueblo sabe la forma en que su gobierno funciona es que el primero estará cumpliendo con el papel que la democracia le asigna y hacer de esta democracia realmente efectiva y participativa.

Por otra parte, el acceso a la información tiene una función instrumental esencial. Solamente a través de una adecuada implementación de este derecho, las 
personas pueden saber con exactitud cuáles son sus derechos y qué mecanismos existen para protegerlos.

Así, según Abramovich y Courtis (2000), el DAIP, en su carácter de bien público o colectivo - con carácter instrumental- es una herramienta de concreción de otros derechos, valores o principios. En este sentido, muy tempranamente, la Corte Interamericana de Derechos Humanos, no obstante, la vaga letra de la Convención Americana, sostuvo que quienes están bajo la protección del mencionado instrumento hemisférico tienen no solo el derecho y la libertad de expresar su propio pensamiento, sino también el derecho y la libertad de buscar, recibir y difundir informaciones e ideas de toda índole (2).

En el año 2006, la Corte Interamericana de Derechos Humanos reconoció, por primera vez(3), el derecho de acceso a la información en poder del Estado, estableciendo los estándares que deberán ser seguidos por las normas y las prácticas domésticas de los países que han adherido a la Convención Americana sobre Derechos Humanos, adoptada en San José de Costa Rica en 1969. Un grupo de personas - que encabezaba Marcel Claude Reyes, conocido ambientalista chileno- pidió información al Comité de Inversiones Extranjeras de Chile sobre un proyecto de deforestación que se realizaría en la Región de Magallanes, al sur de ese país, y que podría afectar el ambiente, recibiendo de parte de la Administración requerida una respuesta escasa y deficiente, y sin dar fundamentos para ello. Claude Reyes reclamó, entonces, ante la justicia chilena, sin éxito. Finalmente, agotadas las instancias internas, recurrió al sistema interamericano que terminó condenando al Estado de Chile por haber violado derechos tutelados por la Convención Americana sobre Derechos Humanos; concretamente, el derecho a la libertad de pensamiento y de expresión tutelados en el artículo 13 de ese instrumento hemisférico que en su punto 1 consigna: "Este derecho comprende la libertad de buscar, recibir y difundir informaciones e ideas de toda índole, sin consideración de fronteras, ya sea oralmente, por escrito o en forma impresa o artística, o por cualquier otro procedimiento de su elección". La norma, de este modo, vino a incluir el derecho a recibir la información bajo control del Estado y la obligación positiva del mismo de suministrarla, en forma tal que toda persona pueda acceder a esa información, o recibir una respuesta negativa pero fundamentada, en el caso que el Estado limite el acceso por algún motivo permitido por la Convención.

(2) Corte IDH, Opinión Consultiva OC-5/85 “La Colegiación Obligatoria de Periodistas (artículos 13 y 29 Convención Americana Sobre Derechos Humanos)", considerando 70.

(3) Corte IDH, Claude Reyes y otros vs. Chile, 19 de septiembre de 2006. Recuperado de http:// www.corteidh.or.cr/docs/casos/articulos/seriec_151_esp.pdf 
No obstante que, en nuestra región, como ha advertido la exrelatora para la Libertad de Expresión de la OEA, Catalina Botero, aún es muy fuerte la cultura del secreto en el ámbito estatal, en los últimos años, ha habido notables avances para el derecho humano de acceso a la información pública, habiendo aprobado leyes en la materia varios países del hemisferio.

Ahora, si bien la adopción de una ley de acceso a la información pública es la plataforma sobre la cual la realización de este derecho se debe construir, ello no es suficiente para lograr la plena realización de este derecho (Mendel, 2009). También es necesario que los órganos estatales estén preparados para almacenar, archivar, producir y proporcionar información a pedido de los ciudadanos o espontáneamente, esto es, de manera proactiva o rutinaria, sin esperar a que le lleguen solicitudes puntuales. Esto, porque si bien el derecho a la información suele asociarse con el derecho a solicitar y recibir información, esta es solo una modalidad mediante la cual se ejercita el derecho, pero no la única, ni, por cierto, la más importante, si se parte de la premisa de que esa información le pertenece al pueblo. Y, por ello, también es que no es necesario que el eventual peticionante acredite un interés personal o motivación concreta en la obtención de la información requerida, como sostiene la Corte Interamericana.

El motivo está presupuesto, ya que se relaciona directamente con la condición de ciudadano y con el derecho a conocer los actos realizados por el gobierno. Insistimos en que, en un régimen democrático, en todo lo referido a los asuntos públicos, la publicidad debe ser la regla y el secreto la excepción (Bobbio, 2013).

\section{III.1. El Acceso a la Información Pública en el Derecho Internacional}

La Declaración Universal de Derechos Humanos, adoptada en 1948 y considerada la piedra angular de todo el Sistema Internacional de Protección de los Derechos Humanos, en su artículo 19, reconoce que

Todo individuo tiene derecho a la libertad de opinión y de expresión; este derecho incluye el de no ser molestado a causa de sus opiniones, el de investigar y recibir informaciones y opiniones, y el de difundirlas, sin limitación de fronteras, por cualquier medio de expresión.

Por su parte, el Pacto Internacional de Derechos Civiles y Políticos de 1966 consagra en su artículo 19.2:

Toda persona tiene derecho a la libertad de expresión; este derecho comprende la libertad de buscar, recibir y difundir informaciones e ideas de toda índole, sin consideración de fronteras, ya sea oralmente, 
por escrito o en forma impresa o artística, o por cualquier otro procedimiento de su elección.

Estos instrumentos internacionales no contemplaron específicamente un "derecho a la información", y sus previsiones generales de libertad de expresión no fueron entendidas, al momento de su adopción, en el sentido de incluir el derecho de acceder a la información que está en manos de entidades estatales. Sin embargo, tal como ha sostenido reiteradamente la Corte Interamericana de Derechos Humanos - y su par europea- los tratados de derechos humanos son instrumentos que deben interpretarse evolutivamente, conforme a las condiciones de vida de la época. Así, más allá de las palabras utilizadas, actualmente se entiende que estas normas incluyen el derecho a la información en el sentido del derecho a solicitar y recibir la información que está en manos del Estado.

En el ámbito interamericano, el artículo 13.1 de la Convención Americana sobre Derechos Humanos tiene una cláusula más garantista aún que los instrumentos de la ONU. En efecto, allí se consigna:

Toda persona tiene derecho a la libertad de pensamiento y de expresión. Este derecho comprende la libertad de buscar, recibir y difundir informaciones e ideas de toda índole, sin consideración de fronteras, ya sea oralmente, por escrito o en forma impresa o artística, o por cualquier otro procedimiento de su elección.

Es que la interdependencia entre el derecho a la información y la libertad de expresión es evidente.

Así, en 1985 la Corte Interamericana, interpretando el citado artículo 13 CADH, hizo referencia a la naturaleza doble del derecho a la libertad de expresión, que protege tanto el derecho a impartir, como el de buscar y recibir, información e ideas, advirtiendo que esta norma

(...) establece que las personas a quienes sea aplicable la Convención no solo tienen el derecho y la libertad de expresar sus propios pensamientos sino además el derecho y la libertad de buscar, recibir e impartir información e ideas de toda clase (...). [La libertad de expresión] requiere, por un lado, que nadie sea limitado ni impedido arbitrariamente de expresar sus propios pensamientos. En tal sentido, es un derecho que corresponde a cada individuo. Su segundo aspecto, por otro lado, implica un derecho colectivo de recibir cualquier información en absoluto y de tener acceso a los pensamientos expresados por otras personas. 
También declaró que "para el ciudadano normal, es tan importante conocer las opiniones de los demás o tener acceso a la información en general como su derecho de impartir su propia opinión", concluyendo que "una sociedad que no esté bien informada es una sociedad que no está verdaderamente libre" (4). Y, aunque este tribunal no llegó, en aquel entonces, a reconocer explícitamente el derecho de acceder a la información que está en manos del Estado, sí estableció un sólido fundamento para dicho reconocimiento posterior.

Dos décadas más adelante en una decisión pionera(5), a la cual ya hicimos referencia, ratificó que la garantía general de libertad de expresión en el referido artículo 13 implica, para los individuos, recibir dicha información, y para los Estados, la obligación positiva de proporcionarla en tal forma que la persona pueda tener acceso para conocer la información o recibir una respuesta motivada cuando, por alguna razón reconocida por la propia Convención, el Estado limite el acceso en un caso particular. Además, dicha información debe ser entregada sin necesidad de acreditar un interés directo para su obtención o una afectación personal, salvo en los casos en que se aplique una legítima restricción, la que, para ser admisible, deberá estar previamente fijada por ley, responder a un objetivo previsto en la Convención - asegurar el respeto a los derechos o a la reputación de los demás, la protección de la seguridad nacional, el orden público, la salud o la moral públicas-, ser necesaria en una sociedad democrática, y ser proporcional al interés que la justifica y conducente para alcanzar el logro de ese objetivo legítimo, como también interferir en la menor medida posible en el efectivo ejercicio del derecho.

Como corolario de lo expuesto en este segmento, delinearemos cuales son los estándares interamericanos sobre acceso a la información pública. En efecto, de la normativa y la jurisprudencia del Sistema Interamericano surgen inequívocamente ciertos estándares que precisan el alcance y contenido del derecho de acceso a la información pública. A saber: i) la legitimación activa debe ser amplia; ii) el Estado tiene la obligación de suministrar la información solicitada, salvo cuando los datos pedidos estuvieren reservados o exceptuados taxativamente por la ley; iii) debe partirse, además, del principio de máxima publicidad, de tal manera que cualquier información en manos de las instituciones públicas debe ser completa, oportuna y accesible; iv) el obligado a otorgar información es el Estado en su conjunto (nacional, provincial, municipal); v) los plazos para que la administración de respuesta deben ser breves; vi) el acceso a la información pública debe ser gratuito; vii) es imprescindible que en caso de falta de respuesta en el plazo estipulado o ante una respuesta parcial o ambigua, se garantice la posibilidad de reclamar la protección del derecho ante la justicia; viii) es imperioso también el

(4) Corte IDH, OC-5/85, 13 de noviembre de 1985, párrafos 30, 32 y 70.

(5) Corte IDH, caso “Claude Reyes y otros vs. Chile. Fondo, Reparaciones y Costas" 19/09/2006. 
establecimiento de un órgano autónomo especializado que supervise el cumplimiento de la normativa involucrada y que resuelva las controversias que surjan entre el solicitante y el Estado; ix) los Estados deben tomar medidas más estructurales, tales como: diseñar un plan de implementación del acceso a la información pública con el consiguiente presupuesto; adoptar normas, políticas y prácticas que permitan conservar y administrar adecuadamente la información; derogar normas y eliminar prácticas contrarias a un acceso amplio y sin escollos a la información pública; entrenar y capacitar a los funcionarios públicos.

\section{El Derecho de Acceso a la Información Pública en nuestro país}

En nuestro país, enormes obstáculos políticos y culturales demoraron la adopción de una ley nacional de acceso a la información pública. Desde 2001 hubo un sin fin de esfuerzos frustrados por parte de organizaciones de la sociedad civil y de algunos legisladores que fueron presentando - sin éxito- proyectos en ambas cámaras del Congreso. A comienzos de 2014, la misma Corte Suprema de Justicia al ratificar su doctrina anterior sobre el acceso a la información pública, enfatizó que esta información "no pertenece al Estado sino que es del pueblo de la Nación Argentina" resaltando, además, la necesidad imperiosa - por constituir "un verdadero reclamo social en nuestro país" - de que se sancionase una ley de alcance nacional que estableciese "con alcance general, pautas uniformes que permitan hacer efectivo este derecho" (6). Dicha ley recién logró ser realidad hace poco más de dos años (7).

La Corte Suprema de Justicia de la Nación(8), el primer caso en el que de manera explícita, amplia y contundente reconoció este derecho (Cenicacelaya, 2014), a actores no estatales que reciban fondos o beneficios públicos, directa o indirectamente; lleven a cabo funciones públicas, como el suministro de servicios públicos o exploten recursos públicos. Más aún, la provisión de información siempre debe ser completa, adecuada, oportuna y veraz; y la denegatoria debe ser la excepción. En la práctica, muchas veces esta denegatoria no es expresa. Habitualmente se niega el acceso a la información a través de la dilación u omisión de la respuesta. Por este motivo, se impone establecer legalmente plazos breves para que se satisfaga la solicitud planteada, contribuyendo de este modo a que la administración brinde una adecuada respuesta a los requerimientos de los ciudadanos.

(6) CSJN, “CIPPEC c/ EN - Ministerio de Desarrollo Social - dto. 1172/03 s/ amparo ley 16.986", 2014, Fallos 337:256.

(7) Ley 27.275, BO 29-09-2016.

(8) CSJN, “ADC c/ PAMI", 2012, Fallos 335: 2393. 
Y para cuando el acceso a la información fuere denegado en sede administrativa es necesario que la legislación prevea expresamente el acceso a la justicia. Si una vez presentado el requerimiento, y cumplido el plazo estipulado en la ley, la solicitud de información no se hubiera satisfecho o la respuesta a la requisitoria hubiere sido ambigua o parcial, debe considerarse que existe negativa en brindarla, quedando expedita la vía judicial. Los jueces también tienen, así, una responsabilidad fundamental: la de proteger el derecho a la información a través de sus sentencias cuando las personas a las que se les negó el acceso a la información pública acuden a sus estrados en reclamo del derecho fundamental violado (9).

Entre los puntos a destacar de la reciente ley 27.275, como sostiene Gelli (2016) debemos mencionar que, en línea con los estándares del Sistema Interamericano, regula el derecho de toda persona a conocer la información pública requerida, de todos los poderes del Estado Nacional. Además, establece que quien hace el pedido no necesita identificarse ni fundamentar su solicitud, ya que es su pleno derecho el conocer el funcionamiento de los organismos públicos. En cuanto a la entrega de información, esta debe hacerse en formatos digitales y abiertos, permitiendo que sean usados, reutilizados y redistribuidos libremente por cualquier persona.

Asimismo, la inclusión de los principios de gratuidad y máxima divulgación, la creación de órganos de control en los tres poderes y el deber por parte de los sujetos obligados de implementar políticas de transparencia activa fortalecen significativamente el DAIP. No obstante, la norma también merece algunas observaciones; entre ellas, las excepciones que refieren a la protección de datos personales - que pueden dar lugar a interpretaciones restrictivas cuando se trate de información de agentes públicos en ejercicio de sus funciones- y a las empresas con participación estatal sujetas al régimen de oferta pública (Fuentes y Cenicacelaya, 2017).

Resulta importante mencionar que, de momento, los estándares de la ley nacional no han sido receptados en todo el país, mediante la adecuación o creación de leyes provinciales (cuando no las hubiere o no respetaran dichos estándares, por caso, la Provincia de Buenos Aires) y ordenanzas municipales, inexistentes en la mayoría de los municipios.

(9) El tema de la evolución jurisprudencial del DAIP en nuestro país se encuentra desarrollado con mayor detenimiento en Fuentes y Cenicacelaya (2017). 


\section{El acceso a la información ambiental en el ámbito internacional}

Ingresando en vertiente más específica de este desarrollo, observaremos como el derecho humano de acceso a la información pública, se convierte en un derecho instrumental para la que los ciudadanos puedan ejercer acciones en protección del ambiente. A dicho respecto, vale reseñar que la presión selectiva sobre los elementos de la naturaleza se fue incrementando a media que se producían los cambios tecnológicos de los últimos dos siglos, y ello impacto fuertemente sobre el medio natural, al punto que motivó que los seres humanos comenzaran a tomar conciencia de las graves consecuencias que esa práctica aparejaría en su existencia.

A partir del último tercio del siglo XX esa preocupación hizo que se adoptaran una serie de instrumentos internacionales que dieron lugar a lo que podemos denominar la globalización de la tutela ambiental, del mismo modo que con anterioridad, había surgido la globalización de la protección de los derechos humanos (Cenicacelaya y Fuentes, 2018).

En tal sentido, afirmamos que resulta más que evidente que contar con información apropiada y completa relativa al ambiente y a los recursos naturales, constituye un instrumento propicio para poder prevenir actos susceptibles de afectarlos de un modo no deseado. Pero, además, para Sabsay y Tarak (1997), ello mejora los niveles de conciencia ciudadana sobre los problemas del ambiente, mejora también su compromiso y accionar participativo, aumenta el control sobre la administración pública incrementando la transparencia y las decisiones más razonadas, e incrementa la confianza de los ciudadanos en la gestión pública. A su turno, la administración también se beneficia pues se puede ampliar la base informativa de las autoridades públicas ambientales a partir de las contribuciones provenientes de la sociedad, mejorar la calidad de las decisiones públicas al contar con una ciudadanía más y mejor informada, demostrar una gestión transparente, y recuperar su credibilidad.

En orden a lo anterior, muy tempranamente, la pionera Declaración de la Conferencia de las Naciones Unidas sobre el Medio Humano, adoptada en Estocolmo, Suecia, el 5 de junio de 1972, estableció la importancia de la educación en cuestiones ambientales (10).

(10) Principio 19: "Es indispensable una labor de educación en cuestiones ambientales, dirigida tanto a las generaciones jóvenes como a los adultos y que preste la debida atención al sector de población menos privilegiado, para ensanchar las bases de una opinión pública bien informada y de una conducta de los individuos, de las empresas y de las colectividades, inspirada en el sentido de su responsabilidad en cuanto a la protección y mejoramiento del medio en toda su dimensión humana. Es también esencial que los medios de comunicación de masas eviten contribuir al deterioro del 
En el mismo sentido, dos décadas más tarde, la Declaración de la Conferencia de las Naciones Unidas sobre Medio Ambiente y Desarrollo, adoptada en Río de Janeiro el 5 de junio de 1992, con mayor precisión consignó las cuestiones ambientales deben ser tratadas sobre la base de la participación de los ciudadanos (11). Además, en ese mismo momento, los Estados miembros de las Naciones Unidas, al acordar la Declaración de Rio, se comprometieron a llevar adelante una serie de acciones englobadas en lo que se llamó la Agenda 21, en donde, entre otros acuerdos, se estableció elaborar programas nacionales eficaces para el examen y el cumplimiento de leyes nacionales, estatales, provinciales y locales sobre el medio ambiente y el desarrollo, estableciéndose diversas acciones a tomar a fin de que los países modificasen ciertos comportamientos a fin de lograr un desarrollo sustentable.

En relación con la información pública el Capítulo 40 (Información para la adopción de decisiones) establece la necesidad de mejorar el acceso a la información debiendo reforzarse los mecanismos nacionales e internacionales de procesamiento e intercambio de información y la asistencia técnica conexa a fin de que haya un acceso efectivo y equitativo a la información generada en los planos nacional, regional e internacional; fortalecerse la capacidad nacional, en el gobierno, en las organizaciones no gubernamentales y en el sector privado, a los efectos del manejo y la comunicación de la información, especialmente dentro de los países en desarrollo; y asegurarse la plena participación, en especial de los países en desarrollo, en cualquier plano internacional en el marco de los órganos y organizaciones del sistema de las Naciones Unidas para la reunión, el análisis y la utilización de los datos y la información.

A veinte años de la histórica Cumbre de la Tierra, la Conferencia de las Naciones Unidas sobre el Desarrollo Sostenible (Río + 20) fue también una oportunidad para que la comunidad internacional manifestara su convicción acerca de que la participación ciudadana en la toma de decisiones puede mejorar la calidad y la aceptación de las decisiones en asuntos ambientales, siendo el acceso a la información ambiental un presupuesto condicionante de dicha participación; y

medio humano y difundan, como, por el contrario, información de carácter educativo sobre la necesidad de protegerlo y mejorarlo, a fin de que el hombre pueda desarrollarse en todos los aspectos".

(11) Principio 10: "El mejor modo de tratar las cuestiones ambientales es con la participación de todos los ciudadanos interesados, en el nivel que corresponda. En el plano nacional, toda persona deberá tener acceso adecuado a la información sobre el medio ambiente de que dispongan las autoridades públicas, incluidas la información sobre los materiales y las actividades que ofrecen peligro en sus comunidades, así como la oportunidad de participar en los procesos de adopción de decisiones. Los estados deberán facilitar y fomentar la sensibilización y la participación del público poniendo la información a disposición de todos (...)". 
constituyendo ambas —información y participación — base de la democracia y la buena gobernanza ambiental(12).

En el mismo sentido se pronuncia la doctrina más autorizada

La protección del ambiente solo se tornará efectiva en todo el planeta cuando dos derechos caminaren juntos: el derecho a la información y el derecho a la participación. Esos derechos tornan posible que los pueblos puedan vivir, en el presente y en el futuro, con equilibrio ecológico y con salud integral, con democracia duradera y disfrute justo y ecuánime de los recursos ambientales (Leme Machado, 2006, p. 265).

Hoy en día, a esos dos derechos debe sumársele un tercero, el derecho a acceder a la justicia para asegurar el cumplimiento de los derechos ambientales o, eventualmente, el resarcimiento por daños sufridos. Esa tríada de derechos interdependientes conforma lo que se ha dado en denominar "los derechos de acceso" en materia ambiental, claves a la hora de asegurar la realización de los compromisos asumidos en la Agenda 2030 (Objetivos para el Desarrollo Sostenible). El acceso a la información favorece la apertura y transparencia en la toma de decisiones, lo que contribuye a forjar la confianza, permite demostrar la existencia de problemas no visualizados con anterioridad o plantear soluciones alternativas, y aumenta la eficiencia y eficacia de las políticas y regulaciones ambientales. La participación (informada) es, a su vez, un mecanismo para integrar las preocupaciones y el conocimiento de la población en las decisiones de política públicas que afectan al ambiente, contribuyendo a prevenir futuros conflictos socio-ambientales. Y el acceso a la justicia proporciona a los individuos, grupos y organizaciones una herramienta para proteger sus derechos ambientales y de acceso a la información y participación en la toma de decisiones, permitiéndoles acceder a procedimientos administrativos y judiciales transparentes, equitativos, oportunos e independientes, que contemplen la reparación y remediación por daño ambiental en caso de afectación de esos derechos por parte del propio Estado o de particulares(13).

En el ámbito hemisférico, en 2012 en el marco de la Conferencia Río + 20, un grupo de países (Chile, Costa Rica, Jamaica, México, Panamá, Paraguay, Perú,

(12) Así, en el documento final adoptado en 2012, Punto 44, se estableció: "El futuro que queremos", puede leerse: "Reconocemos el papel de la sociedad civil y la importancia de posibilitar que todos los miembros de la sociedad civil participen activamente en el desarrollo sostenible. Reconocemos también que la mejora de la participación de la sociedad civil está supeditada, entre otras cosas, a la ampliación del acceso a la información y a la creación de capacidad de la sociedad civil y de un entorno propicio".

(13) CEPAL, Acceso a la información, la participación y la justicia en asuntos ambientales en América Latina y el Caribe. Hacia el logro de la Agenda 2030 para el desarrollo sostenible, ONU, Santiago, 2018, p. 13. 
EL ACCESO A LA INFORMACIÓN PÚBLICA COMO DERECHO HUMANO INSTRUMENTAL PARA LA TUTELA DEL AMBIENTE - CARLOS GonZAlo F. Fuentes

República Dominicana y Uruguay) a dos décadas de la Cumbre de la Tierra, firmaron la Declaración sobre la Aplicación del Principio 10 de la Declaración de Río sobre el Medio Ambiente y el Desarrollo (denominado principio de "democracia ambiental") en la que se reconocía que los derechos de acceso (a la información, participación y justicia) en materia ambiental son esenciales para la promoción del desarrollo sostenible, de la democracia y de un ambiente sano. Asimismo, la Declaración comprometía a los firmantes a explorar la viabilidad de un instrumento regional para asegurar la implementación cabal de estos derechos. Luego, en 2014, se aprobó la Decisión de Santiago, mediante la cual se dio inicio a la negociación del instrumento regional, con la Comisión Económica de Naciones Unidas para América Latina y el Caribe (CEPAL) (14).

Finalmente, el 4 de marzo de 2018, representantes de los gobiernos y de la sociedad civil de veinticuatro países de la región reunidos en Escazú, Costa Rica, adoptaron el Acuerdo Regional sobre el Acceso a la Información, la Participación Pública y el Acceso a la Justicia en Asuntos Ambientales en América Latina y el Caribe(15).

El objetivo de dicho acuerdo - que contó con el auspicio de ONU Medio Ambiente-es, según su artículo 1:

Garantizar la implementación plena y efectiva en América Latina y el Caribe de los derechos de acceso a la información ambiental, participación pública en los procesos de toma de decisiones ambientales y acceso a la justicia en asuntos ambientales, así como la creación y el fortalecimiento de las capacidades y la cooperación, contribuyendo a la protección del derecho de cada persona, y de las generaciones presentes y futuras, a vivir en un medio ambiente sano y al desarrollo sostenible.

Los principios que guían la implementación del mismo, en línea con el derecho internacional de los derechos humanos y las reglas de la democracia ambiental son, en virtud de lo estipulado en su artículo 3: igualdad y no discriminación; transparencia y principio de rendición de cuentas; no regresión y progresividad; buena fe; preventivo; precautorio; equidad intergeneracional; máxima publicidad; soberanía permanente de los Estados sobre sus recursos naturales; igualdad soberana de los Estados; y pro persona. Y por imperio del artículo 4, cada Parte deberá

(14) Comisión Económica de Naciones Unidas para Europa (UNECE), Convenio sobre el acceso a la información, la participación del público en la toma de decisiones y el acceso a la justicia en materia de medio ambiente.

(15) Conocido como LAC P10 - Latin American and Caribbean Countries Principle 10-. Recuperado de https://negociacionp10.cepal.org/9/es 
garantizar el derecho de toda persona a vivir en un ambiente sano, así como cualquier otro derecho humano universalmente reconocido que esté relacionado con el Acuerdo; y, por ello, deberá adoptar todas las medidas necesarias, de naturaleza legislativa, reglamentaria, administrativa u otra, en el marco de sus disposiciones internas, para garantizar su implementación(16).

\section{El acceso a la información ambiental en Argentina}

La reforma constitucional de 1994 se produjo en Argentina cuando el mundo transitaba la segunda ola de preocupación global por cuestiones ambientales (17), fruto de un creciente consenso científico mundial acerca de la gravedad de la situación del ambiente y los bienes naturales. Esa revisión de la ley suprema plasmó una amplia tutela del ambiente en diversas normas: una central (artículo 41) que en sus cuatro párrafos excede largamente la mera consagración a nivel federal del derecho al ambiente; otra procesal (artículo 43 , párrafo $2^{\circ}$ ) y variadas referencias incidentales como la que otorga a los pueblos indígenas el derecho a participar en "la gestión referida a sus recursos naturales" (artículo 75, inc. 17); las menciones al "desarrollo humano" (artículos 75, inc. 19, párrafo $1^{\circ}$ y 125 , párrafo $2^{\circ}$ ), y el reconocimiento a las provincias del "dominio originario de los recursos naturales" (artículo 124, párrafo $2^{\circ}$ ). Además de esas referencias explícitas, por la vía de otorgamiento de jerarquía constitucional a varios instrumentos internacionales (artículo 75, inc. 22, párrafo $2^{\circ}$ ) completa la constitucionalización de los derechos ambientales con el PIDESC que, aunque se refiere a derechos de la segunda generación, incluye dentro del contexto del derecho a la salud de toda persona, el mejoramiento del ambiente (artículo 12.b) (18).

En su primer párrafo el artículo $41 \mathrm{CN}$ establece que "todos los habitantes gozan del derecho a un ambiente sano, equilibrado, apto para el desarrollo humano

(16) El Acuerdo estará abierto a la firma de los treinta y tres países de América Latina y el Caribe, en la sede de las Naciones Unidas en Nueva York, a partir del 27 de septiembre de este año, y estará sujeto a la ratificación de los Estados que lo hayan firmado. Durante la segunda reunión del Foro de los Países de América Latina y el Caribe sobre el Desarrollo Sostenible, realizado el pasado abril en la sede de la CEPAL en Santiago se hizo un llamado a los países de la región a ratificar este acuerdo "visionario y sin precedentes" que "vincula explícitamente lo ambiental con los derechos humanos y garantiza derechos procedimentales que son esenciales para implementar de manera adecuada la Agenda 2030 para el Desarrollo Sostenible". Recuperado de https://www.cepal.org/es/noticias/ llaman-paisesamerica-latina-caribe-ratificar-primer-acuerdo-regional-asuntos-ambientales

(17) La primera había sucedido veinte años atrás como respuesta — sobre todo en el mundo desarrollado- al desenfrenado desarrollo industrial de posguerra.

(18) Y, a su vez, al atribuirse a todos los tratados internacionales jerarquía superior a las leyes (artículo 75 , inc. 22, párr. $1^{\circ}$ in fine), se rejerarquizan varios tratados (bi o multilaterales) sobre aspectos parciales de la cuestión ambiental que completan la protección constitucional. 
y para que las actividades productivas satisfagan las necesidades presentes sin comprometer las de las generaciones futuras; y tienen el deber de preservarlo". Esta obligación de preservar el ambiente, que opera como reverso del derecho al ambiente, es una especificación del clásico y genérico alterum non laedere (Quiroga Lavié, 2009), y se complementa con lo dicho en el $3^{\circ}$ párrafo: "Las autoridades proveerán a la protección de este derecho". Es decir, como el ambiente es cosa de todos, su protección no es confiada solo a los gobernantes, sino que, además de ser una obligación del Estado, es también un deber de los ciudadanos (Prieur, 1991). Ahora bien, para que esa participación ciudadana sea posible, es necesario que se cuente con la información pertinente. Por ello, es que ese mismo párrafo $3^{\circ}$ establece que las autoridades también deben proveer a la información ambiental, generando la obligación estatal de informar públicamente a la población de todo aquello que esté en condiciones de generar un daño ambiental actual o potencial, lo que implica la eliminación del secreto tanto en el ámbito público como privado, y no limitándose ese deber solo a recolectar datos y proporcionarlos a la ciudadanía, sino que los mismos deberán ser elaborados, ordenados y procesados a fin de que sea de fácil acceso para los particulares.

Por su parte, si bien la Constitución Nacional no reconoce de forma expresa el derecho de acceso a la información pública (ambiental o de cualquier otra índole), entre los tratados que gozan de jerarquía constitucional (artículo 75 inc. 22) sí podemos afirmar que este derecho, con distintos matices, se halla tutelado (19).

Más aún, a partir de la doctrina del control de convencionalidad desarrollada por la Corte Interamericana de Derechos Humanos, los Estados parte de la Convención Americana sobre Derechos Humanos deben ajustar sus normas y sus prácticas no solo al mencionado tratado sino también a otros instrumentos de derechos humanos y a las decisiones de los órganos internacionales encargados de su interpretación y aplicación (20). Y ello comprende, incluso, lo que señale la Corte Interamericana en ejercicio de su competencia consultiva (21).

En relación con esto último, debemos recordar que el 15 de noviembre de 2017 la Corte Interamericana dio a conocer su primera opinión consultiva relativa a

(19) No solo en el artículo 13 de la Convención Americana sobre Derechos Humanos que, como ya dijimos, permitió que la Corte Interamericana reconociera por vez primera pretorianamente el DAIP en un conflicto que, precisamente, involucraba cuestiones ambientales, Corte IDH ("Claude Reyes y otros vs. Chile", 2006), sino también en la Declaración Universal de Derechos Humanos (artículo 19) y en el Pacto Internacional de Derechos Civiles y Políticos (artículo 19).

(20) Corte IDH "Almonacid Arellano y otros vs. Chile”, 2006; “Trabajadores cesados del Congreso (Aguado Alfaro y otros) vs. Perú”, 2006; “Cabrera García y Montiel Flores vs. México”, 2010; “Gelman vs. Uruguay", 2011.

(21) Corte IDH OC-21/14, párrafo 31. 
cuestiones ambientales(22). En ella manifiesta que, para garantizar el cumplimiento de las obligaciones ambientales de prevención, precaución, mitigación del daño y cooperación interestatal, el derecho internacional de los derechos humanos impone determinadas obligaciones de procedimiento a los Estados, tales como el acceso a la información, la participación pública y el acceso a la justicia (párrafo 106). Y en directa vinculación con ello, saluda como una medida positiva para garantizar el derecho de acceso a la información en esta materia, el proceso de adopción del Acuerdo LAC P10 (párrafo 218) que, como ya referimos, estaba en curso en ese momento. Además, luego de recordar que en su sentencia de 2006 en el caso "Claude Reyes y otros vs. Chile" ya sostuvo que el artículo $13 \mathrm{CADH}$ protege el derecho que tiene toda persona a solicitar el acceso a la información de interés público bajo control del Estado, la Corte resalta que constituyen asuntos de evidente interés público el acceso a la información sobre actividades y proyectos que podrían tener impacto ambiental (párrafo 213 y 214).

El derecho de las personas a obtener información ambiental se ve complementado, dice la Corte, con una correlativa obligación positiva del Estado de suministrar la máxima cantidad de información en forma oficiosa; información que debe ser completa, oportuna, comprensible, en un lenguaje accesible, encontrarse actualizada y brindarse de forma que sea efectiva para los distintos sectores de la población(23). Esta obligación implica tanto la provisión de mecanismos y procedimientos para que las personas individuales soliciten la información (sin tener que demostrar un interés específico) como la recopilación y difusión activa de información por parte del Estado. Además, el Tribunal advierte que esta obligación de transparencia activa cobra particular importancia en casos de emergencias ambientales que requieren la difusión inmediata y sin demora de la información relevante y necesaria para cumplir con el deber de prevención (párrafo 220 a 225).

El artículo $41 \mathrm{CN}$ también establece en su $3^{\circ}$ párrafo que en materia ambiental le "Corresponde a la Nación dictar las normas que contengan los presupuestos mínimos de protección, y a las provincias, las necesarias para complementarlas, sin que aquellas alteren las jurisdicciones locales". De este modo, las provincias han cedido a la Nación la atribución de dictar el marco o base en materia ambiental; "piso" inderogable para las provincias que mantienen en su ámbito territorial la competencia de desenvolver y desarrollar el marco nacional a tenor de las

(22) Corte IDH OC-23/17, Medio Ambiente y Derechos Humanos.

(23) Tal como establecen las Directrices para la Elaboración de Legislación Nacional sobre el Acceso a la Información, la Participación del Público y el Acceso a la Justicia en Asuntos Ambientales (Directrices de Bali), adoptadas en Bali el 26 de febrero de 2010 por el Consejo de PNUMA, Decisión SS. XI/5, Parte A, Directriz 1. 
circunstancias especiales de su territorio y las singularidades y especificidades de sus problemas ambientales.

En los veinticinco años transcurridos desde la aparición de esta novedosa fórmula de reparto de competencias dentro del Estado federal argentino, se han dictado una decena de leyes de "presupuestos mínimos" en materia ambiental; entre las que cabe destacar, a los fines de este trabajo, la Ley General del Ambiente, 25.675(24), y la Ley de Libre Acceso a la Información Pública Ambiental, $25.831(25)$.

En razón de que el sistema ambiental implica una complejidad que trasciende las fronteras políticas, su preservación de un país descentralizado territorialmente requiere de una política coordinada que distribuya las competencias de manera articulada entre las diferentes jurisdicciones (Morales Lamberti y Novak, 2006). Así, la ley 25.675 consigna que uno de los objetivos de la política ambiental nacional es establecer un sistema federal de coordinación inter-jurisdiccional, para la implementación de políticas ambientales de escala nacional y regional(26) y que el Sistema Federal Ambiental (instrumentado a través del Consejo Federal de Medio Ambiente -COFEMA-) tiene por objeto desarrollar la coordinación de la política ambiental, tendiente al logro del desarrollo sustentable, entre el gobierno nacional, los gobiernos provinciales y el de la Ciudad de Buenos Aires(27).

La ley también incluye, entre los objetivos de la política ambiental nacional, organizar e integrar la información ambiental y asegurar el libre acceso de la población a la misma (28); que es, a su vez, uno de los instrumentos de la política y la gestión ambiental(29). El carácter relevante que la norma le da a la información ambiental se reafirma más adelante al establecer que toda persona -física o jurídica, pública o privada - y no solo las autoridades, deberá proporcionar la información que esté relacionada con la calidad ambiental y referida a las actividades que desarrolle pudiendo todo habitante obtener de las autoridades la información ambiental que administren y que no se encuentre contemplada legalmente como reservada (30). A su turno, la autoridad de aplicación deberá desarrollar un sistema nacional integrado de información que administre los datos significativos y relevantes del ambiente, y evalúe la información ambiental disponible; debien-

\footnotetext{
(24) BO 28-11-2002.

(25) BO 07-01-2004.

(26) Artículo 2.j.

(27) Artículo 23.

(28) Artículo 2.i.

(29) Artículo 8.5.

(30) Artículo 16.
} 
do, asimismo, proyectar y mantener un sistema de toma de datos sobre los parámetros ambientales básicos, estableciendo los mecanismos necesarios para la instrumentación efectiva a través del COFEMA(31). Las autoridades son, además, responsables de informar sobre el estado del ambiente y los posibles efectos que sobre él puedan provocar las actividades antrópicas actuales y proyectadas; debiendo el Poder Ejecutivo, a través de los organismos competentes, elaborar un informe anual sobre la situación ambiental del país que presentará al Congreso de la Nación, conteniendo un análisis y evaluación sobre el estado de la sustentabilidad ambiental en lo ecológico, económico, social y cultural de todo el territorio nacional (32). Para dar cumplimiento a esto, el Ministerio de Ambiente y Desarrollo Sustentable de la Nación publicó el 20 de abril de 2017 el último Informe del Estado del Ambiente -2016 - que fuera presentado al Congreso de la Nación, en formato digital. Es un trabajo que puede ser consultado en la web(33).

Por ser el acceso a la información pública, como ya dijimos, un requisito previo e imprescindible para la participación ciudadana, ya que quien esté desinformado o informado de manera inexacta o parcial, no tendrá la posibilidad de participar adecuadamente en los procesos de toma de decisión, la ley también se ocupa de esta cuestión expresamente (34), mientras que, para completar la tríada de los denominados "derechos de acceso", a la legitimación para el acceso a la justicia se la vincula al amparo ambiental previsto por el artículo 43, párrafo $2^{\circ} \mathrm{CN}(35)$.

Valiéndose de las normas precitadas, la Corte Suprema de Justicia de la Nación en su primera decisión en la emblemática causa de la Cuenca Matanza-Riachuelo resolvió en el Punto V.5 requerir al Estado Nacional, a la provincia de Buenos Aires, a la ciudad de Buenos Aires y al COFEMA para que en el plazo de treinta días y en los términos de la ley 25.675 presentasen un plan integrado (conf. artículo 5) basado en el principio de progresividad (conf. artículo 4) que contemplase un programa de información ambiental pública a todo el que la requiriera, especialmente los ciudadanos del área territorial involucrada (conf. artículos 16 y 18)(36).

En virtud de la supremacía interpretativa que la ley 25.675 asumió frente a las demás leyes ambientales federales, (37) sus normas — de orden público-prevalecen

(31) Artículo 17.

(32) Artículo 18.

(33) Recuperado de https://www.argentina.gob.ar/sites/default/files/mayds_informe_estado_ ambiente_2016_baja_1_0.pdf

(34) Artículos 2.c. y 19 a 21.

(35) Artículos 31 y ss.

(36) CSJN, Mendoza, "Beatriz Silvia y otros c/ Estado Nacional y otros s/ daños y perjuicios (daños derivados de la contaminación ambiental del río Matanza - Riachuelo)”, 2006, Fallos 329: 2316.

(37) Artículos 3 y 4. 
sobre las de la ley 25.831, la cual, por ser de presupuestos mínimos es, a su vez, el marco de las leyes locales que normen la materia (Valls, 2016). Por ello, la última impone a las autoridades nacionales y locales concertar criterios para homogeneizar los procedimientos de acceso a la información ambiental en cada jurisdicción, siempre en el marco del COFEMA(38).

La información ambiental, cuyo libre acceso garantiza esta última, es la que se relaciona con la protección del ambiente, los recursos naturales o culturales que lo integran y el desarrollo sustentable (39), que obre en poder del Estado, al quien la ley 25.675 le encomendó generarla, elaborarla, analizarla y evaluarla. De ahí que, el sujeto pasivo sea exclusivamente el sector público, estatal, y no estatal, en todas sus esferas (40). Mientras que el sujeto activo es toda persona, física o jurídica, no necesitándose invocar razones ni interés determinado y siendo gratuito el acceso, salvo los gastos vinculados con los recursos utilizados para su provisión(41) que debe hacerse en un plazo máximo de treinta días (42). La autoridad solo podrá denegar la entrega de la información solicitada por decisión fundada y por darse los excepcionales supuestos previstos en la ley (43). Y debe, además, cooperar para facilitar el acceso a la información ambiental, promoviendo la difusión del material informativo que se genere (44).

\section{Consideraciones conclusivas}

Como hemos visto, la evolución de la democracia moderna no solo se agota en que el ciudadano ejerza sus derechos en plenitud, sino que, además, implica la obligación de los entes estatales - en todos sus niveles- de compartir la información obrante en sus registros cuando la misma sea de utilidad como insumo a los requerimientos de la sociedad. En dicha faena, ciudadanos y organizaciones de la sociedad civil, que luchan por incrementar los componentes participativos y deliberativos de la democracia, han forjado una concepción que, bajo la denominación genérica de "gobierno abierto", sienta las bases para un tránsito hacia una modalidad de gestión pública más transparente, participativa y colaborativa entre estado y sociedad civil.

\footnotetext{
(38) Artículo 5.

(39) Artículo 2.

(40) Artículos 1 y 4.

(41) Artículo 3.

(42) Artículo 8.

(43) Artículo 7.

(44) Artículo 6.
} 
Para que ello ocurra, resulta inexorable que la sociedad civil tenga poder real frente al Estado a los efectos de, conocer para controlar y peticionar para corregir eventuales decisiones públicas equivocadas, a fin de elegir o mudar las elecciones políticas. Con ello sin dudas favoreceremos el desarrollo de democracias genuinas y sustentables.

En ese orden, un ineludible principio consagratorio del estado abierto, lo constituye el derecho humano de acceso a la información pública que, como hemos reseñado, en relación con la protección ambiental, resulta crucial para garantizar una responsable, colectiva y vigorosa participación ciudadana, en aras del cumplimiento de la cláusula constitucional de preservar el ambiente.

Los datos aquí reseñados, demuestran que estamos transitando un progresivo desarrollo evolutivo del derecho de acceso a la información pública, y sus principios consagratorios, también se propagan hacia la legislación ambiental.

\section{Bibliografía}

Abramovich, V. y Courtis, C. (2000). El acceso a la información como derecho. Anuario de Derecho a la Comunicación, Año 1 Vol. 1. Buenos Aires: Siglo XXI.

Ackerman, J. y Sandoval, I. (2005). Leyes de acceso a la información en el mundo. Cuadernos de Transparencia, Instituto Federal de Acceso a la Información, Cuaderno No 07. México.

Basterra, M. I. (2006). El derecho fundamental de acceso a la información pública. Buenos Aires: Lexis Nexis.

Bobbio, N. (2013). Democracia y secreto. México: Fondo de Cultura Económica.

Botero Marino, C. (2011). Problemas persistentes y desafíos emergentes en materia de libertad de expresión en las Américas. En C. Rodríguez Garavito (coord.), El derecho en América Latina. Un mapa para el pensamiento jurídico del siglo XXI. Buenos Aires: Siglo XXI, 272.

Cenicacelaya, M. (2014). La Corte Suprema reconoce un derecho fundamental: el derecho de acceso a la información pública. Anales, Revista de la Facultad de Ciencias Jurídicas y Sociales, Universidad Nacional de La Plata, No 44 (pp. 73-77). Buenos Aires: Thomson Reuters.

Cenicacelaya, M. y Fuentes, C. G. (2018). Naturaleza y derechos humanos. En: L. F. Pastorino (Dir.), Las formas de la naturaleza y las formas de su regulación (pp. 35-50). Buenos Aires: Ediciones Cooperativas. 
Comisión Interamericana de Derechos Humanos (2010). El derecho de acceso a la información en el marco jurídico inter-americano. Relatoría Especial para la Libertad de Expresión, OEA-CIDH, Washington.

Comisión Interamericana de Derechos Humanos (2015). El derecho de acceso a la información pública en las Américas: entidades especializadas para la supervisión y el cumplimiento. Relatoría Especial para la Libertad de Expresión, OEA $\mathrm{CIDH}$, Washington.

Fayt, C. S. (2005). La omnipotencia de la prensa. Buenos Aires: La Ley.

Fuentes, G. y Cenicacelaya, M. (2017). El acceso a la información pública como sustrato esencial del gobierno abierto. Actas BIREDIAL-ISTEC VII Conferencia Internacional sobre Bibliotecas y Repositorios Digitales de América Latina (BIREDIAL-ISTEC'17), XII Simposio Internacional de Bibliotecas Digitales (SIBD'17) Editorial Universidad Nacional de La Plata, Institución de origen: Ibero-American Science and Technology Education Consortium (ISTEC), 269-287. Recuperado de http://sedici.unlp.edu.ar/handle/10915/63614

Gelli, M. A. (2016). Ley de acceso a la información pública, los principios, los sujetos obligados y las excepciones. Diario La Ley 27/09/2016. Buenos Aires: La Ley.

Leme Machado, P. A. (2006). Direito à informação e meio ambiente, São Paulo: Malheiros.

Martín Mateo, R. (1991). Tratado de Derecho Ambiental, Tomo I. Madrid: Trivium.

Mendel, T. (2009). El Derecho a la Información en América Latina. Quito: UNESCO.

Morales Lamberti, A. y Novak, A. (2006). Instituciones de Derecho Ambiental. Córdoba: Lerner.

Nikken, P. (1994). El concepto de derechos humanos. En: Estudios básicos de derechos humanos, Instituto Interamericano de Derechos Humanos, San José, Costa Rica.

Nino, E. (2008). El derecho a recibir información pública -y su creciente trascendencia - como derecho individual y de incidencia colectiva. En: R. Gargarella (coord.), Teoría y crítica del Derecho Constitucional (pp. 797-817). Buenos Aires: Abeledo Perrot. 
Oszlak, O. (2016). Estado Abierto, la próxima frontera. Buenos Aires: Diario La Nación, 18 de abril.

Prieur, M. (1991). Droit de l'environnement. Paris: Dalloz.

Quiroga Lavié (2009). Derecho Constitucional Argentino. Buenos Aires: Rubinzal-Culzoni.

Rosanvallon, P. (2015). La contra democracia. La política en la era de la desconfianza. Buenos Aires: Ed. Manantial.

Saba, R. (2004). El derecho de la persona a acceder a la información en poder del gobierno en Derecho Comparado de la Información № 3. México: Universidad Autónoma de México.

Sabsay, D. y Tarak, P. (1997) El acceso a la información pública, el ambiente y el desarrollo sustentable. Fundación Ambiente y Recursos Naturales Manual № 3. Buenos Aires: FARN.

Valls, M. F. (2016). Derecho Ambiental. Buenos Aires: Abeledo Perrot.

Fecha de recepción: 26-03-2019 Fecha de aceptación: 15-09-2019 